\title{
A Review on Biosurfactant Applications in the Petroleum Industry
}

\author{
Wei Xi $\mathbb{D}^{1,2}$ Yuanye Ping $\mathbb{D}^{1},{ }^{1}$ and Masoome Agha Alikhani $\mathbb{D}^{3}$ \\ ${ }^{1}$ College of Primary Education, Zhengzhou Normal University, Zhengzhou, Henan 450044, China \\ ${ }^{2}$ Xinjiang Institute of Ecology and Geography, Chinese Academy of Sciences, Ürümqi, Xinjiang 830011, China \\ ${ }^{3}$ Fouman Faculty of Engineering, College of Engineering, University of Tehran, Fouman, Iran
}

Correspondence should be addressed to Yuanye Ping; yuanyeping@126.com and Masoome Agha Alikhani; m.aghaalikhani@ ut.ac.ir

Received 23 July 2021; Revised 9 August 2021; Accepted 19 August 2021; Published 31 August 2021

Academic Editor: Alireza Baghban

Copyright (C) 2021 Wei Xi et al. This is an open access article distributed under the Creative Commons Attribution License, which permits unrestricted use, distribution, and reproduction in any medium, provided the original work is properly cited.

\begin{abstract}
The inadequacy of worldwide fossil fuel resources, combined with increasing energy demands, encourages global attention to either using alternative energy resources or improving the recovery factor and produce larger quantities from present reservoirs. Among all enhanced oil recovery (EOR) methods, surfactant injection is a well-known technique that reduces the interfacial tension (IFT) between oil and water and increases oil production. Despite numerous advantages of using surfactants, there are also a few obstacles like environmental impacts, high cost, effect on humans and other organisms due to toxicological potential, and availability from nonrenewable resources. Biosurfactants are microbial surface-active agents that decrease the surface tension (ST) of a liquid phase and the IFT of two diverse phases. They are biotechnological products of high value owing to their widespread applications, low toxicity, relatively easy preparation, and specific performance, applied in different industries like organic chemicals and fertilizers, agrochemicals, metallurgy and mining, cosmetics, foods, medical and pharmaceuticals, beverages, environmental management, and petroleum and petrochemical applications in emulsifying and demulsifying wetting agents, detergent spreading and foaming agents, and functional food ingredients. Biosurfactants are synthesized by microbes; therefore, various genetic diversities of microorganisms provide the considerable capability to produce new types of biosurfactants, which can develop EOR technology. Biosurfactants are classified into ex situ and in situ MEOR processes. The genera Pseudomonas, Bacillus, Sphingomonas, and Actinobacteria are the foremost biosurfactant-producing bacteria. This paper reviews relevant reports and results from various presented papers by researchers and companies on applications of microorganisms and biosurfactant technology with specific emphasis on EOR and MEOR processes, based on recently published articles since 2010 until now.
\end{abstract}

\section{Introduction}

These days, human life is highly dependent on fossil fuel and its related products such as kerosene, gas, petrol, and diesel $[1,2]$. Among the various fossil fuel types, crude oil plays an essential role in the industrial revolution since the beginning of civilizations to provide global energy supplies [1, 3]. Statistics of global oil resources consumption exhibit an increasing trend from the last century until 2019. As a primary energy source, oil consumption was about 36390.5 Mbbl in 2019, and much increase has been assumed for the future, which would increase oil prices [4]. Figure 1 shows the global crude oil consumption trend from 1980 until now and predicts growing consumption demand in the future.
The graph experienced a reduction in 2020 due to the worldwide coronavirus pandemic and widespread shutdowns; however, an increase in worldwide energy demand is expected in the approaching decades [5]. Rising universal energy demands, in addition to limited fossil fuel resources across the world, require a robust response to energy supply. Development and improvement of the oil recovery technique yield from the existing reservoirs; furthermore, identifying alternative resources is the best way to reduce dependence on fossil fuels in the future [6-9].

Various alternatives have been developed and suggested, including wind energy, solar energy, nuclear energy, and different biomass-converted products such as firewood, biogas, fuel pellets, biodiesel, bioethanol, bio-oil, and 


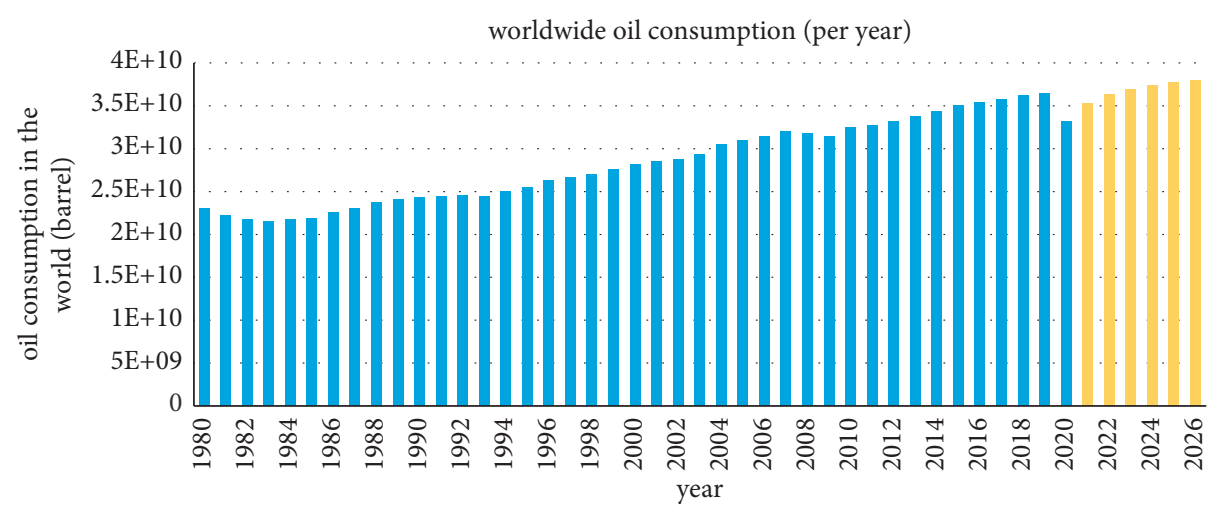

FIgURE 1: Worldwide consumption of oil resources (barrel per year) [5].

biohydrogen [10-14]. Despite the availability and advantages of renewable resources, their technology and investigations are in the initial stages, also requiring fossil fuel-based infrastructure changes $[15,16]$. Some cases are not cost-effective in comparison with fossil fuels; therefore, fossil fuels remain the essential energy resource, applied for household and industrial purposes, power generation, and transportation [17-20].

There are a number of considered techniques for enhancing oil recovery from depleted reserves [21]. The procedure of recovering oil from reservoirs includes primary, secondary, and tertiary recovery phases [22-24]. In the first recovery phase, oil production is driven by the reservoir's initial pressure energy, which can produce just $10-20 \%$ of the present oil in the reservoir $[25,26]$. In the second recovery phase, either gas or water will be injected to the reservoir to maintain both reservoir and oil pressures during production, and the final oil recovery phase increases $20-40 \%[21,26-28]$. To determine the amount of relative oil and water saturation, choosing appropriate injection fluid, chemical factors, and reservoir conditions such as pressure, temperature, brine characterization, pollution levels, rock type and sizes, and distribution of pores structure information is essential [29-31]. If the injected fluid's viscosity is lower than the displacing fluid, the injected compound may flow faster than the initial compound's flow across the porous media $[32,33]$. Depending on oil properties, geographic difficulties, and reservoir conditions, initial and secondary oil production methods are capable of producing $40-60 \%$ of the original oil in place (OOIP), while residual oil saturation $\left(S_{\text {or }}\right)$ is a target for EOR $[21,26,28,34]$. The most economically viable time to apply EOR methods in a field seems to be at the early stages after primary recovery; however, the best time usually depends on the economic factors of the production process $[34,35]$. Figure 2 represents an overview of the field development program and three production stages.

High IFT between oil and water combined with high capillary force and electrostatic charge causes a large amount of unrecovered oil to be trapped in the pores $[3,36,37]$. To decrease residual oil value and improve oil recovery yields, improved and upgraded technologies such as enhanced oil recovery (EOR) have been employed in secondary or tertiary stages [26, 37]. A significant difference between EOR and conventional reservoir recovery techniques like water and gas injection is that EOR mobilizes the remaining oil in the porous media for more economical outcomes, further extending the lifetime of reservoirs and prolonging crude oil production [38-41]. IFT of the injecting fluid has a crucial role in EOR. The high value of IFT between injected water and the oil prevents oil displacement, resulting in a high amount of unrecovered oil in reservoirs. Meanwhile, decrease in IFT caused by the EOR fluid reduces and mobilizes the unrecovered oil value and enhances microscopic sweep efficiency [32, 33, 42-44]. The second reason for low oil recovery and oil remaining in the pores is capillary forces, which can be overcome by using the EOR methods [33, 45].

To demonstrate the effect of capillary forces, the nondimensional capillary number has been considered as the ratio of fluid viscosity $(\mu)$ to velocity $(V)$, IFT $(\sigma)$ between oil and water, and contact angle $(\theta)$ [46-48]. As this ratio increases by four or five orders in the magnitude of an EOR process, the residual oil volume will reduce, which requires either an IFT decline or adjusting the contact angles for a moderate wettability, which is nearly 90 degree of interphase ( $\theta)[46,48]$.

\section{A Review of EOR and MEOR Methods}

The EOR methods mainly include injecting a particular fluid with chemical, thermal (in situ combustion, injecting steam), or microbial characteristics into the reservoir [21, 23, 37, 49-53]. Thomas provided a detailed classification of EOR methods [54]. MEOR (microbial enhanced oil recovery) is an EOR technique that utilizes microorganisms and their metabolic products, which can produce nearly $30 \%$ of the remaining oil in the reservoir [55]. A considerable number of EOR techniques employ chemical methods due to their easy applicability and easy access to various chemical compounds. Meanwhile, the MEOR methods continue to gain attention because of their improved applicability, environmental friendly nature, and competitive prices $[21,56-58]$. The existence of various microorganisms with different metabolite productions and growing properties affects the used recovery method. There are three feasible mechanisms to use biosurfactants in the MEOR processes: 


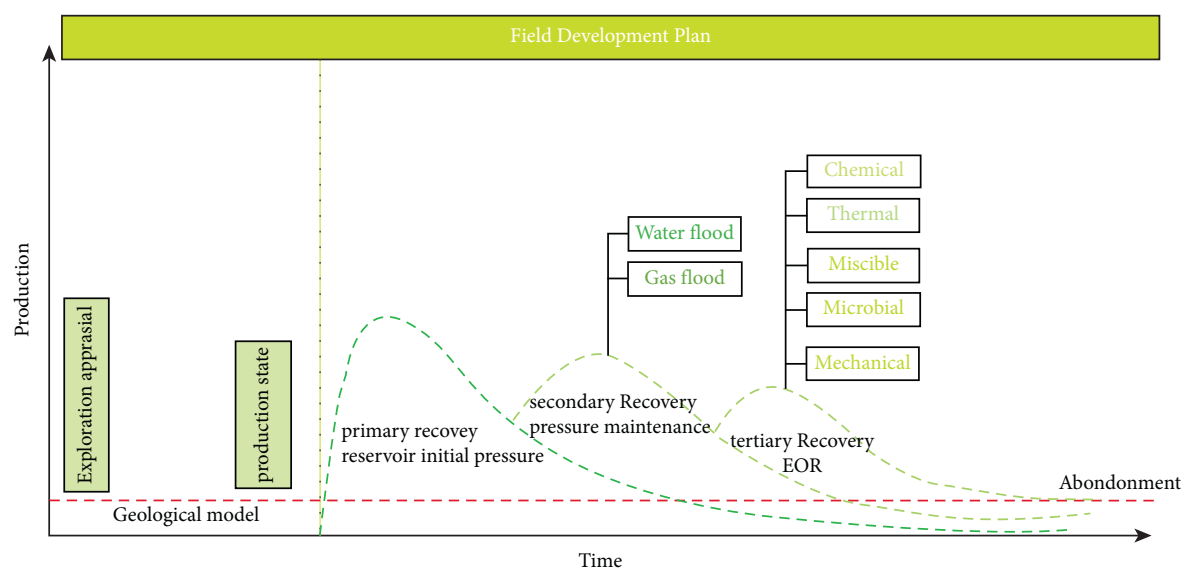

FIGURE 2: Various stages of petroleum production (inspired from [1]).

(1) Injecting biosurfactant-producing microorganisms from wells toward the reservoir and consequent in situ diffusion by the reservoir rock

(2) Injecting appropriate nutrients inside the reservoir to stimulate the reservoir's biosurfactant-producing endemic microorganisms to grow

(3) Producing biosurfactants in ex situ bioreactors and injecting them subsequently into the reservoir $[59,60]$

Chemical EOR, a highly effective EOR method, includes surfactant injection, polymer injection, acid and alkaline flooding, and injecting other suitable chemical compounds within the reservoir to alter the interactions between crude oil/brine/rock (COBR) and properties and enhance oil recovery $[53,61,62]$. In polymer injection for enhanced oil recovery, polymers are dispersed into water to increase water viscosity and then injected into the reservoir in order to reach a greater capillary number, higher vertical sweep power, and also increased upward-moving control $[63,64]$. Alkaline flooding is another powerful EOR method to recover heavy oil, which has been used in many projects since 1970 [42, 65, 66]. Notwithstanding other methods, this method has no limitation about depths or formation thicknesses and needs no high-cost surface equipment. The reaction between alkali and the acidic compound of heavy oil forms surface-active materials, which reduces IFT by ionization at the water-oil interface by several orders of magnitude [67].

Various experiments have been performed in other branches of chemical EOR, using alkaline surfactants (ASs), alkaline polymers (APs), and alkaline surfactant polymers (ASPs), which has attracted interest as one of the most effective techniques [47, 68]. Delshad et al. [69] simulated Chinese onshore oil reservoir characteristics using a specific method to measure the amount of recovered oil. Surfactant polymer, alkaline, and ASP flooding methods were examined where the alkaline surfactant polymer flooding method increased 24\% of OOIP further recovery in comparison with using only water and produced the least value for residual oil. Synthetic chemicals are generally derived from fossil fuels, have high prices, and cause inappropriate environmental influences. Surfactant flooding includes injecting either chemical surfactants or biosurfactants and natural surfactants into the reservoir [9]. Both biosurfactants and chemical surfactants decrease IFT at the interface and surface tension at the surface by accumulating between the liquid phases [70, 71]. Chemical surfactants and polymers are generally expensive, hazardous, and subtend several obstacles, such as undesirable residues that are hard to dispose, environmental impacts, and linking with fossil fuels. The natural surfactants are classified in the same way as chemical surfactants into amphoteric, nonionic, cationic, and anionic types, and they have a nature-based source, for example, saponin derived from Zizyphus spina-christi leaves, nonionic surfactants derived from Glycyrrhiza glabra, and cationic surfactants from olive, Prosopis, spistan, and Seidlitzia rosmarinus [70-72]. Several articles have investigated the application of chemical surfactants and their effect on the water and oil IFT in EOR projects, due to relatively lower costs. Biosurfactants have been reviewed for their potential to be used in petroleum production, especially to achieve eco-friendly biodegradable surfactants.

\section{Surfactants}

The use of surfactants dates back 2,800 years in soap production [73]. The global production of surfactants has grown to over 13 million tons every year as one of the most widely used industrial chemicals, half of which is used as laundry and household detergents $[74,75]$. Surfactants include both hydrophilic and hydrophobic domains as a group of amphiphilic chemical compounds, which makes it an essential component in most modern industries like agriculture (i.e., organic chemicals and fertilizers), agrochemicals, metallurgy, mining, cosmetics, foods, paper, public health and pharmaceuticals, beverages, environmental management, textiles, petroleum, petrochemicals, and bioremediation $[72,74,76,77]$.

Taking advantage of petrochemical and oleochemical resources, organochemical synthesis produces most of the surfactants used in the industry today. Hence, most of the surfactants used today are petroleum-derived, which is problematic due to environmental incongruity and toxic 
effects on humans and the environment, leading to major ecological problems since they inevitably enter the environment after use [74]. Use of surfactants is an increasing concern due to their biodegradability, toxicity, bioaccumulation, and phosphate releases [78]. The environmental community should make efforts to decrease detergent loads and biodegradable use since detergents release phosphates. The extensive diversity and large volumes of applications have been a significant drive to move forwards in producing surfactants from natural and renewable feedstock, which are biosurfactants. An extended genetic variety of microorganisms provides the substantial capability of forming new sorts of biosurfactants from the natural fermentation process instead of organochemical-synthesized surfactants. The following section discusses microbially produced biosurfactants and effective parameters in the EOR process.

\section{Biosurfactants}

Biosurfactants are a group of amphiphilic compounds with antiviral, hemolytic, insecticidal, and antimicrobial biological activities. They are applicable in numerous industries, including foods, cleaning products, pharmacology (drug solvents), cosmetics, pesticides, textiles, fungicides on different organic surfaces, medicine, and oil and gas fields as essential biotechnology products [7, 79]. The growing interest in biosurfactants is because of their low environmental impacts, low toxicity, and biodegradability [80]. The global market for biosurfactants reached 1.5 billion USD until 2019, which is assumed to experience over a 5.5\% CAGR by 2026, of which over half of it belongs to Europe [7]. Household detergents, cosmetics, personal care, and the food industry account for the highest application market $[7,81]$.

By 1960, the first biosurfactants were synthesized via microbes throughout hydrocarbon fermenting in the form of extracellular compounds [82]. They are generated on living surfaces and can reduce ST as well as IFT. The best production grounds for them are extracellular hydrophilic and hydrophobic moieties or surfaces of microbial cells [83]. Due to growing awareness of the adverse effects of chemical surfactants on the environment, interests have shifted toward environment-friendly surfactants [80, 84]. Affective factors in producing biosurfactants are carbon content, $\mathrm{pH}$, the type of the nitrogen source, temperature, aeration, and carbon-to-nitrogen Ratio [74, 76]. Evonik, Jeneil Biotech, Biotensidon, and Ecover are the major biosurfactant-producing companies; also, genera Pseudomonas, Bacillus, Sphingomonas, and Actinobacteria include the foremost biosurfactant-producing bacteria. Desai and Banat [80] provided a detailed review of biosurfactants, and we will only focus on biosurfactants that may be useful for improving oil recovery such as glycolipids, rhamnolipids, lipopeptides, and sophorolipids.

Özdemir et al. [83] compared the interfacial tension reduction in two pure rhamnolipid solutions. They found that molecules of rhamnolipids have strong intermolecular interactions, thus resulting in excellent foam-formation properties even at a narrow air flow rate. However, other yeast biosurfactants, including sophorolipids and glycolipids, had moderate foaming abilities.

Joshi-Navare et al. [85] produced and investigated sophorolipids (SLs) from nonedible Jatropha oil and realized their effectiveness in removing stains. They optimized fermentation parameters to maximize Jatropha oil-derived SL yield (SLJO), which demonstrated a significant ability to decrease the ST in distilled water, coupled with antibacterial and stain-removing capabilities, in addition to good emulsion stability under $\mathrm{pH}$ stress and temperature. Reduced immersion time during the washing process accompanying their antibacterial activity, biodegradability, and skin-friendly properties make them ideal alternatives for synthetic surfactants in household detergents to reduce their adverse effects.

Sajna et al. [86] studied a Pseudozyma sp. NII08165 biosurfactant containing a combination of some unknown glycolipid and three mannosylerythritol lipid (MEL) isomers. Their stability over the alkaline $\mathrm{pH}$ range and high temperatures make them suitable as laundry detergent additives to remove stains efficiently. Figure 3 compares the yield of various biosurfactant-producing microorganisms. Some biosurfactant yields are not exactly presented in reviewed articles, and we did not mention them in the figure and used accurate data.

\section{Application of Biosurfactants in EOR Methods}

The foaming property of biosurfactants allows use of them in various sectors, such as reducing oil viscosity and cleaning crude oil storage tanks as detergents. Several researchers have been investigating the usage of biosurfactants in EOR operations. The cost of biosurfactants is generally higher than chemical surfactants, making EOR less viable commercially, but they perform better than their chemical counterparts due to higher environmental compatibility, reduced toxicity, and ability to be generated from renewable sources [87]. Utilizing cheaper raw materials, optimizing media components, hyperproduction, or using fermentation extracts that contain significant amounts of biosurfactants can reduce the cost $[2,57]$. Biosurfactant use for EOR can be divided into ex situ and in situ MEOR procedures, called biosurfactant-mediated MEOR (BS-MEOR) [59]. In the former, laboratory-produced biosurfactants are injected into the reservoir, while the in situ process identifies proper microorganisms present in the reservoir and supports their growth to synthesize needed metabolites, for instance, surfactants or polymers that provide favorable factors for EOR [88]. Following this phase, wells are shut in and monitored for microbial activity and metabolite production. There has been a successful substantial increase in oil production resulting from MEOR field-scale in situ research projects.

Lal [89] constructed a combined microbial consortium consisting of three hyperthermophilic, acidogenic, and barophilic anaerobic strains to improve oil recovery from oil reservoirs under $70^{\circ} \mathrm{C}$ to $90^{\circ} \mathrm{C}$ temperature, resulting in various metabolic outputs like alcohols, biosurfactants, 


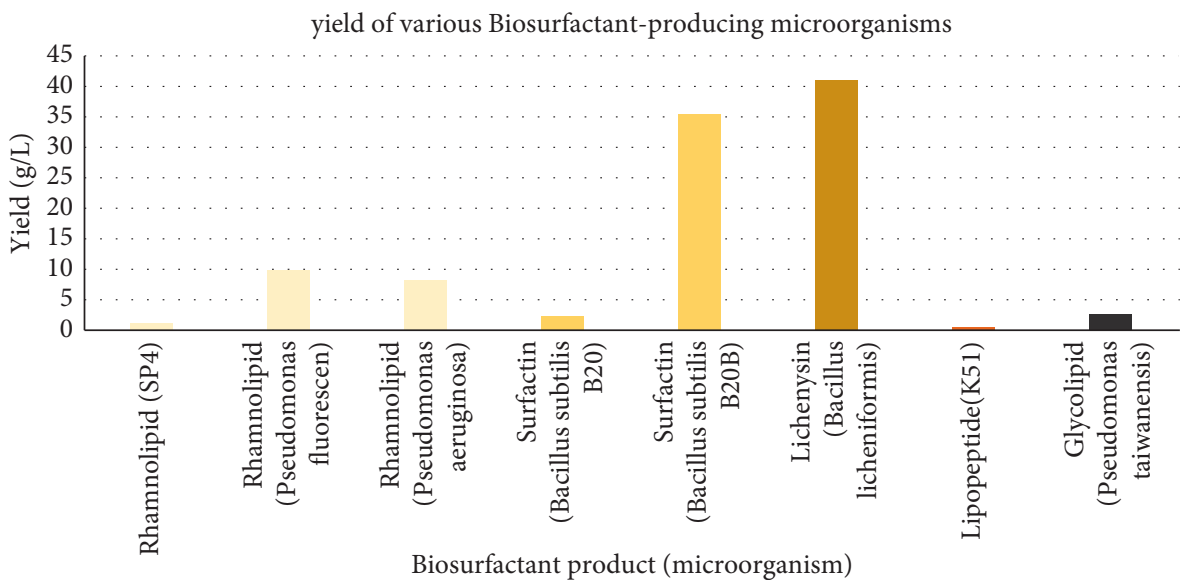

FiguRE 3: Yield of various biosurfactant-producing microorganisms (data extracted from [82]).

methane, volatile fatty acids, and $\mathrm{CO}_{2}$ under the specially designed nutrient medium. In situ application of the microbial consortium provided an oil-improving recovery process and increased the efficiency of sweeping crude oil from oil-bearing poles of rock formations. Studies of the MEOR applications mainly focus on two types of biosurfactants: glycolipids and lipopeptides [90]. Lipopeptides show greater efficacy in reducing IFT and ST $[90,91]$.

Cooper et al. [92] studied surfactin production on a large scale by Bacillus subtilis. They discovered that surfactin was recoverable from collapsed foam through acid precipitation. Glucose substrate fermentation by sequential product removal by foam fractionation resulted in a good yield, which also increased via the application of iron or manganese salts. B. subtilis completely stopped producing surfactin when hydrocarbon was added to the medium, which regularly improves biosurfactant production. By reducing the $\mathrm{pH}$ to 2.0, the surfactin precipitates from Bacillus subtilis culture spent media, and after extracting dichloromethane and reprecipitating it with acid, it can be better purified.

Biochemical investigation on one of the JF-2 proteins exhibited a similar amino acid composition and infrared spectrum to surfactin but the JF-2 acid precipitate has other components that may be necessary for interactions between all components and JF-2 as full activity surfactant. Following this, required solvents have been developed for complete activity and interaction among these compounds. Among four present components in the crude extract, chloroform, dichloromethane, and methanol could extract sequentially 1 , 2 , and 4 components with $23 \%, 56 \%$, and $94 \%$ values of activity recovery, respectively. Reconstituted surfactant preparation was performed more actively than preparation of individual extracted components in experiments [92, 93].

Cooper and Goldenberg [94] obtained that the monoglyceride biosurfactant produced by $B$. cereus increased the polyhexosamine emulsifier activity by this organism.

Investigations of McInerney et al. [93] and Jenneman et al. [95] on the JF-2 surfactant revealed promising properties for enhanced oil recovery. Those concentrations where $\mathrm{NaCl}$ was at least $5 \%(\mathrm{w} / \mathrm{v})$ provided the lowest IFT; thus, the JF-2 biosurfactant is more effective when the $\mathrm{NaCl}$ concentration is high. Oil reservoirs have high levels of salt, which are the ideal conditions for the organism to grow. Very low CMC of JF-2 makes it an effective biosurfactant in dilute concentrations; the IFT was obtained less than $0.1 \mathrm{mN} / \mathrm{m}$. High biosurfactant concentrations or cosurfactants may result in lower IFT.

McInerney et al. [93] studied anaerobic biosurfactant production from Bacillus licheniformis strain JF-2 growing in a medium consisting of glucose-mineral salts, $\mathrm{NaNO}_{3}$, and yeast extract. By decreasing the $\mathrm{pH}$ to 2.0 , an anionic biosurfactant precipitated from the spent medium, which resulted in a substantial decline of the ST in the medium from 70 to $74 \mathrm{mN} / \mathrm{m}$ to as low as $28 \mathrm{mN} / \mathrm{m}$. Both JF- 2 and surfactin biosurfactants reduced water surface tension by $27 \mathrm{mN} / \mathrm{m}$, the lowest determined surface tension for biosurfactants. B. subtilis completely stopped producing surfactin when hydrocarbon was added to the mechanism, which normally boosts biosurfactant production. By reducing the $\mathrm{pH}$ to 2.0, the surfactin precipitates from Bacillus subtilis culture spent media, which can be further purified by dichloromethane extraction and reprecipitation with acid.

Arima et al. [96] characterized surfactin, an efficient biosurfactant synthesized from Bacillus strains, as it possesses high surface activity and a low critical micelle concentration (CMC) comparable to synthetic surfactants. Lipopeptide surfactin inhibits fibrin clot formation and induces lowered surface tension and reduced interfacial tension against a hexadecane concentration of less than $1 \mathrm{mN} / \mathrm{m}$. It is stable under high $\mathrm{pH}$ conditions, high salinity conditions, and high temperatures. Furthermore, low CMC characteristics may be advantageous for EOR applications since they impact the economy of EOR development [97, 98].

McInerney et al. [93] grew and synthesized biosurfactants using Bacillus mojavensis JF-2 anaerobically along with other competing organisms in a sand environment. Bacillus mojavensis JF-2 grew fastest on glucose; besides, monosaccharides tended to be the preferred sources of carbon generally. The highest growing yield was observed with fructose. Under anaerobic conditions, the presence of peptone \#2 (PP2) in the medium enhanced the production of biosurfactants. 
TABLE 1: Utilized microorganisms and their products.

\begin{tabular}{lcc}
\hline Microorganisms & Growth requirement & Microbial products \\
\hline Clostridium sp. & Anaerobic & Acids, surfactants, gases, alcohols \\
Bacillus licheniformis & Facultative & Acids, surfactants \\
Bacillus sp. & Facultative & Acids, surfactants \\
Gram-negative rods & Facultative & Acids, gases \\
\hline
\end{tabular}

The microbial formulation consists of four microorganisms (NIPER Bac 1) that have been injected into four wells of the Delaware-Childers field in Oklahoma, producing primarily surfactants, alcohols, and acids, followed by regular injections of molasses used as a nutrient [99]. Applied microorganisms and their products are classified separately in Table 1 . After core waterflooding, laboratory microbial tests recovered $28 \%$ of the residual oil.

Bryant et al. [99] performed micromodels to reveal if oil could be mobilized via the microbial formulation in the porous environment and related oil mobilization with oil recovery efficiency in Berea sandstone cores. After micromodel waterflooding, about $60 \%$ of the oil has been mobilized. When the micromodel was incubating, gas bubbles were observed, as well as crude oil emulsification. NIPER Bac 1 mobilizes oil primarily through gas production, surfactants, and solvents. The initial results showed a $13 \%$ sustainable increase in oil recovery along with decreased surface tension of produced brine, revealing the effectivity of in situ microbial biosurfactant production in recovering additional petroleum. As a definite record that strain JF-2 can grow and manufacture its surfactants all over an oil reservoir, strain JF-2 was detached from the produced brine 30 weeks after injection.

In another study on micromodels, Bryant and Douglas [100] noticed that microorganisms that have a high recovery efficiency in a core flood also perform better in mobilizing crude oil. As microorganisms grow and produce $\mathrm{CO}$ and chemicals, they can significantly enhance oil recovery in reservoirs under suitable salinity and temperature conditions. A microbial study of Berea sandstone cores revealed that ability of bacteria in recovering remaining oil after waterflooding varies widely, ranging from 7.5 to $71 \%$; the type of core encapsulation had no effect on the recovered oil amount. Studies using a wide permeability range (134-1,920) showed that some microorganisms might be more efficient at recovering oil in lower-permeability cores. As a result, some surfactant-producing bacteria enhance oil recovery in ways that no gas-producer microorganisms can do; as a result, gas production is not the only affecting factor. It is also vital to consider the kind of surfactant; two microorganisms can produce surfactants that differ in their recovery capacity. Improving the areal sweep efficiency (EA) of microorganisms appears to be a beneficial mechanism in microbially mobilizing oil. Comparing two heavy oil and medium-to-light-gravity oil recovery yields showed that the MEOR method might be appropriate for both light and heavy oils.

The work of McInerney et al. [93, 101] and other papers $[102,103]$ indicated lower than $0.1 \mathrm{mN} / \mathrm{m}$ interfacial tension between water and oil while using lipopeptides. Lipopeptide surfactants have a poor yield and high manufacturing costs when produced through fermentation; therefore, they are rarely applied in field-scale EOR projects, and utilizing them is limited to industries like paper, health care, pulp, and foods [104].

Long et al. [105] conducted a study on the $\mathrm{pH}$-regulated emulsifying activity of surfactin and its possible application in separating oil in EOR. The results demonstrated that surfactin is able to effectively stabilize emulsions over $\mathrm{pH} 7.4$, which allows easy oil separation by adjusting $\mathrm{pH}$ when using surfactin as an emulsifier. The surfactin-based EOR technique has great application potential since it can be reused multiple times and sustains its activity after demulsification.

\section{Conclusions}

In this study, applied microorganisms on oil fields were explored. Although biosurfactants tend to be more expensive than chemical surfactants, they are preferred due to their environmental compatibility, reduced toxicity, and ability to be produced from renewable resources. Utilizing cheaper raw materials, optimizing media components, hyperproduction, or using fermentation extracts that contain significant amounts of biosurfactants can reduce the cost. Oil recovery can be improved using both in situ and ex situ microorganisms. Utilizing in situ microbial EOR-produced metabolic products such as biosurfactants, alcohols, methane, volatile fatty acids, and $\mathrm{CO}_{2}$ improved oil recovery and sweep efficiency. The effect of different parameters, including $\mathrm{pH}$, concentration, and components, on the behavior of different kinds of Bacillus microorganisms was investigated. An efficient biosurfactant synthesized with low CMC, surfactin, was examined to achieve a low interfacial tension. By optimizing microbial mobilization in the porous environment, oil recovery efficiency was maximized.

\section{Abbreviations}

AS: $\quad$ Alkaline surfactant

ASP: $\quad$ Alkaline surfactant polymer

AP: $\quad$ Alkaline polymer

BS- Biosurfactant-mediated microbial enhanced oil

MEOR: recovery

B. subtilis: Bacillus subtilis

CMC: Critical micelle concentration

COBR: Crude oil/brine/rock

EA: Areal sweep efficiency

EOR: $\quad$ Enhanced oil recovery

IFT: Interfacial tension

OOIP: $\quad$ Original oil in place

MELs: Mannosylerythritol lipids 
MEOR: Microbial enhanced oil recovery

PP2: $\quad$ Proteose peptone \#2

ST: $\quad$ Surface tension

$S_{\text {or: }} \quad$ Residual oil saturation

SLs: $\quad$ Sophorolipids

SLJOs: Jatropha oil-derived sophorolipids.

\section{Data Availability}

The data used to support the findings of this study are included within the article.

\section{Conflicts of Interest}

The authors declare that they have no conflicts of interest.

\section{Acknowledgments}

The authors would like to thank McInerney et al. for the "Properties of the Biosurfactant Produced by Bacillus licheniformis Strain JF-2" article, which was our guide in the preparation of this article.

\section{References}

[1] S. Geetha, I. M. Banat, and S. J. Joshi, "Biosurfactants: production and potential applications in microbial enhanced oil recovery (MEOR)," Biocatalysis and Agricultural Biotechnology, vol. 14, pp. 23-32, 2018.

[2] R. Silva, D. Almeida, R. Rufino, J. Luna, V. Santos, and L. Sarubbo, "Applications of biosurfactants in the petroleum industry and the remediation of oil spills," International Journal of Molecular Sciences, vol. 15, no. 7, pp. 12523-12542, 2014.

[3] Z. Bachari, A. A. Isari, H. Mahmoudi, S. Moradi, and E. H. Mahvelati, "Application of natural surfactants for enhanced oil recovery-critical review," IOP Conference Series: Earth and Environmental Science, vol. 221, Article ID 012039, 2019.

[4] R. Schulz, "The reason to expect prolonged USD 30-60/bbl oil," Journal of Petroleum Technology, vol. 68, no. 10, pp. 42-45, 2016.

[5] N. Sönnichsen, "Daily demand for crude oil worldwide from 2006 to 2026, D.d.f.c.o.w.f.t. 2026," 2021, http://www.statista. com.

[6] S. Ardabili, A. Mosavi, and A. R. Varkonyi-Koczy, "Systematic review of deep learning and machine learning models in biofuels research," Lecture Notes in Networks and Systems, Engineering for Sustainable Future, Springer, Berlin, Germany, 2019.

[7] C. Nikolova and T. Gutierrez, "Biosurfactants and their applications in the oil and gas industry: current state of knowledge and future perspectives," Frontiers in Bioengineering and Biotechnology, vol. 9, Article ID 626639, 2021.

[8] B. Wei, L. Romero-Zerón, and D. Rodrigue, "Oil displacement mechanisms of viscoelastic polymers in enhanced oil recovery (EOR): a review," Journal of Petroleum Exploration and Production Technology, vol. 4, no. 2, pp. 113-121, 2014.

[9] G. J. Hirasaki, C. A. Miller, and M. Puerto, "Recent advances in surfactant EOR," SPE Journal, vol. 16, no. 4, pp. 889-907, 2011.
[10] M. F. Demirbas and M. Balat, "Recent advances on the production and utilization trends of bio-fuels: a global perspective," Energy Conversion and Management, vol. 47, no. 15-16, pp. 2371-2381, 2006.

[11] Y. Chisti, "Biodiesel from microalgae," Biotechnology Advances, vol. 25, no. 3, pp. 294-306, 2007.

[12] S. Ingale, S. J. Joshi, and A. Gupte, "Production of bioethanol using agricultural waste: banana pseudo stem," Brazilian Journal of Microbiology, vol. 45, no. 3, pp. 885-892, 2014.

[13] A. M. Lopez-Hidalgo, A. Sánchez, and A. De LeónRodríguez, "Simultaneous production of bioethanol and biohydrogen by Escherichia coli WDHL using wheat straw hydrolysate as substrate," Fuel, vol. 188, pp. 19-27, 2017.

[14] S. N. Naik, V. V. Goud, P. K. Rout, and A. K. Dalai, "Production of first and second generation biofuels: a comprehensive review," Renewable and Sustainable Energy Reviews, vol. 14, no. 2, pp. 578-597, 2010.

[15] A. Bera and A. Mandal, "Microemulsions: a novel approach to enhanced oil recovery: a review," Journal of Petroleum Exploration and Production Technology, vol. 5, no. 3, pp. 255-268, 2015.

[16] R. Amit, "Petroleum reservoir exploitation: switching from primary to secondary recovery," Operations Research, vol. 34, no. 4, pp. 534-549, 1986.

[17] J. Mohd Ali, M. A. Hussain, M. O. Tade, and J. Zhang, "Artificial intelligence techniques applied as estimator in chemical process systems-a literature survey," Expert Systems with Applications, vol. 42, no. 14, pp. 5915-5931, 2015.

[18] S. A. Scott, M. P. Davey, J. S. Dennis et al., "Biodiesel from algae: challenges and prospects," Current Opinion in Biotechnology, vol. 21, no. 3, pp. 277-286, 2010.

[19] R. Shukla, M. Kumar, S. Chakraborty et al., "Process development for the production of bioethanol from waste algal biomass of Gracilaria verrucosa," Bioresource Technology, vol. 220, pp. 584-589, 2016.

[20] D. G. De Almeida, R. d. C. F. Soares Da Silva, J. M. Luna et al., "Biosurfactants: promising molecules for petroleum biotechnology advances," Frontiers in Microbiology, vol. 7, p. 1718, 2016.

[21] H. Al-Sulaimani, Y. M. Al-Wahaibi, S. Joshi, S. Al-Bahry, A. Elshafie, and A. Al-Bemani, "Microbial biotechnology for enhancing oil recovery: current developments and future prospects," Biotechnology, Bioinformatics and Bioengineering, vol. 1, no. 2, pp. 147-158, 2011.

[22] A. Bera and H. Belhaj, "Ionic liquids as alternatives of surfactants in enhanced oil recovery-a state-of-the-art review," Journal of Molecular Liquids, vol. 224, pp. 177-188, 2016.

[23] S. Kokal and A. Al-Kaabi, "Enhanced oil recovery: challenges \& opportunities," World Petroleum Council: Official Publication, vol. 64, pp. p64-69, 2010.

[24] G. Stosur, "Past, present and what the next 25 years may bring," in Proceedings of the SPE International Improved Oil Recovery Conference in Asia Pacific, Kuala Lumpur, Malaysia, October 2003.

[25] A. Bera, A. Mandal, and B. B. Guha, "Synergistic effect of surfactant and salt mixture on interfacial tension reduction between crude oil and water in enhanced oil recovery," Journal of Chemical \& Engineering Data, vol. 59, no. 1, pp. 89-96, 2014.

[26] L. W. Lake, "Fundamentals of enhanced oil recovery," vol. 1Society of Petroleum Engineers, Richardson, TX, USA, 2014. 
[27] R. T. Bachmann, A. C. Johnson, and R. G. J. Edyvean, "Biotechnology in the petroleum industry: an overview," International Biodeterioration \& Biodegradation, vol. 86, pp. 225-237, 2014.

[28] L. W. Lake, R. L. Schmidt, and P. B. Venuto, "A niche for enhanced oil recovery in the 1990s," Oilfield Review;(Netherlands), vol. 4, no. 1, 1992.

[29] W. W. Owens and D. L. Archer, "The effect of rock wettability on oil-water relative permeability relationships," Journal of Petroleum Technology, vol. 23, no. 7, pp. 873-878, 1971.

[30] G. D. Henderson, A. Danesh, D. H. Tehrani, S. Al-Shaidi, and J. M. Peden, "Measurement and correlation of gas condensate relative permeability by the steady-state method," SPE Reservoir Evaluation and Engineering, vol. 1, no. 2, pp. 134-140, 1998.

[31] R. Nelson, "Cosurfactant-enhanced alkaline flooding," in Proceedings of the SPE Enhanced Oil Recovery Symposium, April 1984.

[32] K. Holmberg, D. O. Shah, and M. J. Schwuger, Handbook of Applied Surface and Colloid Chemistry, Vol. 1, WileyBlackwell, Hoboken, NJ, USA, 2002.

[33] M. A. Ahmadi, Y. Arabsahebi, S. R. Shadizadeh, and S. Shokrollahzadeh Behbahani, "Preliminary evaluation of mulberry leaf-derived surfactant on interfacial tension in an oil-aqueous system: EOR application," Fuel, vol. 117, pp. 749-755, 2014.

[34] S. Park, E. S. Lee, and W. R. W. Sulaiman, "Adsorption behaviors of surfactants for chemical flooding in enhanced oil recovery," Journal of Industrial and Engineering Chemistry, vol. 21, pp. 1239-1245, 2015.

[35] R. Schmidt, "Thermal enhanced oil recovery current status and future needs," Chemical Engineering Progress; (USA), vol. 86, no. 1, 1990.

[36] A. Seethepalli, B. Adibhatla, and K. Mohanty, "Wettability alteration during surfactant flooding of carbonate reservoirs," in Proceedings of the SPE/DOE Symposium on Improved Oil Recovery, Tulsa, OK, USA, April 2004.

[37] P. Raffa, A. A. Broekhuis, and F. Picchioni, "Polymeric surfactants for enhanced oil recovery: a review," Journal of Petroleum Science and Engineering, vol. 145, pp. 723-733, 2016.

[38] A. Sabhapondit, A. Borthakur, and I. Haque, "Water soluble acrylamidomethyl propane sulfonate (AMPS) copolymer as an enhanced oil recovery chemical," Energy \& Fuels, vol. 17, no. 3 , pp. $683-688,2003$.

[39] W. F. Ramirez, Application of Optimal Control Theory to Enhanced Oil Recovery, Elsevier, Amsterdam, Netherlands, 1987.

[40] M. Blunt, F. J. Fayers, and F. M. Orr Jr., "Carbon dioxide in enhanced oil recovery," Energy Conversion and Management, vol. 34, no. 9-11, pp. 1197-1204, 1993.

[41] P. M. W. Cornelisse, C. J. Peters, and J. de Swaan Arons, "Application of the Peng-Robinson equation of state to calculate interfacial tensions and profiles at vapour-liquid interfaces," Fluid Phase Equilibria, vol. 82, pp. 119-129, 1993.

[42] Q. Liu, Interfacial, Phenomena in Enhanced, University of Regina, Regina, Canada, 2006.

[43] J. J. Sheng, "Status of surfactant EOR technology," Petroleum, vol. 1, no. 2, pp. 97-105, 2015.

[44] S. Kumar and A. Mandal, "Studies on interfacial behavior and wettability change phenomena by ionic and nonionic surfactants in presence of alkalis and salt for enhanced oil recovery," Applied Surface Science, vol. 372, pp. 42-51, 2016.
[45] L. L. Schramm, E. N. Stasiuk, and D. Turner, "The influence of interfacial tension in the recovery of bitumen by waterbased conditioning and flotation of Athabasca oil sands," Fuel Processing Technology, vol. 80, no. 2, pp. 101-118, 2003.

[46] T. T. Chau, "A review of techniques for measurement of contact angles and their applicability on mineral surfaces," Minerals Engineering, vol. 22, no. 3, pp. 213-219, 2009.

[47] E. Carrero, N. V. Queipo, S. Pintos, and L. E. Zerpa, "Global sensitivity analysis of alkali-surfactant-polymer enhanced oil recovery processes," Journal of Petroleum Science and Engineering, vol. 58, no. 1-2, pp. 30-42, 2007.

[48] D. Schechter, Z. Denqen, and F. Orr, "Capillary imbibition and gravity segregation in low IFT systems," in Proceedings of the SPE Annual Technical Conference and Exhibition, Dallas, TX, USA, October 1991.

[49] Y. Al-Wahaibi, H. Al-Hadrami, S. Al-Bahry, A. Elshafie, A. Al-Bemani, and S. Joshi, "Injection of biosurfactant and chemical surfactant following hot water injection to enhance heavy oil recovery," Petroleum Science, vol. 13, no. 1, pp. 100-109, 2016.

[50] I. M. Banat, S. K. Satpute, S. S. Cameotra, R. Patil, and N. V. Nyayanit, "Cost effective technologies and renewable substrates for biosurfactantsâ€ production," Frontiers in Microbiology, vol. 5, p. 697, 2014.

[51] S. J. Joshi and R. M. M. Abed, "Biodegradation of polyacrylamide and its derivatives," Environmental Processes, vol. 4, no. 2, pp. 463-476, 2017.

[52] D. Levitt, A. Jackson, C. Heinson; et al., "Identification and evaluation of high-performance EOR surfactants," in Proceedings of the SPE/DOE Symposium on Improved Oil Recovery, Tulsa, OK, USA, April 2006.

[53] A. Gurgel, "A review on chemical flooding methods applied in enhanced oil recovery," Brazilian Journal of Petroleum and Gas, vol. 2, no. 2, 2008.

[54] S. Thomas, "Enhanced oil recovery-an overview," Oil \& Gas Science and Technology-Revue de l'IFP, vol. 63, no. 1, pp. 9-19, 2008.

[55] B. Saharan, R. Sahu, and D. Sharma, "A review on biosurfactants: fermentation, current developments and perspectives," Genetic Engineering and Biotechnology Journal, vol. 2011, no. 1, pp. 1-14, 2011.

[56] I. M. Banat, "Characterization of biosurfactants and their use in pollution removal-state of the art (review)," Acta Biotechnologica, vol. 15, no. 3, pp. 251-267, 1995.

[57] I. Lazar, I. G. Petrisor, and T. F. Yen, "Microbial enhanced oil recovery (MEOR)," Petroleum Science and Technology, vol. 25, no. 11, pp. 1353-1366, 2007.

[58] J. Patel, S. Borgohain, M. Kumar, V. Rangarajan, P. Somasundaran, and R. Sen, "Recent developments in microbial enhanced oil recovery," Renewable and Sustainable Energy Reviews, vol. 52, pp. 1539-1558, 2015.

[59] R. S. Bryant and R. P. Lindsey, "World-wide applications of microbial technology for improving oil recovery," in Proceedings of the SPE/DOE Improved Oil Recovery Symposium, April 1996.

[60] T. Ariadji, D. I. Astuti, P. Aditiawati et al., "Microbial huff and puff project at Mangunjaya field wells: the first in Indonesia towards successful MEOR implementation," in Proceedings of the SPE/IATMI Asia Pacific Oil \& Gas Conference and Exhibition, October 2017.

[61] D. A. Z. Wever, F. Picchioni, and A. A. Broekhuis, "Polymers for enhanced oil recovery: a paradigm for structure-property relationship in aqueous solution," Progress in Polymer Science, vol. 36, no. 11, pp. 1558-1628, 2011. 
[62] M. Baviere, P. Glenat, V. Plazanet, and J. Labrid, "Improvement of the efficiency/cost ratio of chemical EOR processes by using surfactants, polymers, and alkalis in combination," SPE Reservoir Engineering, vol. 10, no. 3, pp. 187-193, 1995.

[63] D. O. Shah, Improved Oil Recovery by Surfactant and Polymer Flooding, Elsevier, Amsterdam, Netherlands, 2012.

[64] A. Bengar, S. Moradi, M. Ganjeh-Ghazvini, and A. Shokrollahi, "Optimized polymer flooding projects via combination of experimental design and reservoir simulation," Petroleum, vol. 3, no. 4, pp. 461-469, 2017.

[65] W. Zhou, "Effects of Surfactant Adsorption and Distribution on Enhanced Heavy Oil Recovery by Alkaline/Surfactant Flooding," M.S. thesis, University of Regina, Regina, Canada, 2004.

[66] E. H. Mayer, R. L. Berg, J. D. Carmichael, and R. M. Weinbrandt, "Alkaline injection for enhanced oil recovery-a status report," Journal of Petroleum Technology, vol. 35, no. 1, pp. 209-221, 1983.

[67] M. Gray, A. Yeung, J. Foght, and H. W. Yarranton, "Potential microbial enhanced oil recovery processes: a critical analysis," in Proceedings of the SPE Annual Technical Conference and Exhibition, October 2008.

[68] S. R. Clark, M. J. Pitts, and S. M. Smith, "Design and application of an alkaline-surfactant-polymer recovery system to the West Kiehl field," SPE Advanced Technology Series, vol. 1, no. 1, pp. 172-179, 1993.

[69] M. Delshad, W. Han, G. A. Pope et al., "Alkaline/surfactant/ polymer flood predictions for the karamay oil field," in Proceedings of the SPE/DOE Improved Oil Recovery Symposium, April 1998.

[70] J. Li, M. Deng, Y. Wang, and W. Chen, "Production and characteristics of biosurfactant produced by Bacillus pseudomycoides BS6 utilizing soybean oil waste," International Biodeterioration \& Biodegradation, vol. 112, pp. 72-79, 2016.

[71] J. F. B. Pereira, E. J. Gudiña, R. Costa et al., "Optimization and characterization of biosurfactant production by Bacillus subtilis isolates towards microbial enhanced oil recovery applications," Fuel, vol. 111, pp. 259-268, 2013.

[72] M. Pacwa-Płociniczak, G. A. Płaza, Z. Piotrowska-Seget, and S. S. Cameotra, "Environmental applications of biosurfactants: recent advances," International Journal of Molecular Sciences, vol. 12, no. 1, pp. 633-654, 2011.

[73] R. Geys, W. Soetaert, and I. Van Bogaert, "Biotechnological opportunities in biosurfactant production," Current Opinion in Biotechnology, vol. 30, pp. 66-72, 2014.

[74] Z. Velioglu and R. O. Urek, "Physicochemical and structural characterization of biosurfactant produced by Pleurotus djamor in solid-state fermentation," Biotechnology and Bioprocess Engineering, vol. 21, no. 3, pp. 430-438, 2016.

[75] G. M. Insights, "Biosurfactants market size by product, by application, industry analysis report, regional outlook, application potential, price trend, competitive market share \& forecast," Global Market Insights, vol. 2023, p. 100, 2016.

[76] I. N. A. Van Bogaert, D. Buyst, J. C. Martins, S. L. K. W. Roelants, and W. K. Soetaert, "Synthesis of bolaform biosurfactants by an engineered Starmerella bombicola yeast," Biotechnology and Bioengineering, vol. 113, no. 12, pp. 2644-2651, 2016.

[77] M. Nitschke and S. G. V. A. O. Costa, "Biosurfactants in food industry," Trends in Food Science \& Technology, vol. 18, no. 5, pp. 252-259, 2007.
[78] D. W. Green and G. P. Willhite, Enhanced Oil Recovery, Vol. 6, Henry L. Doherty Memorial Fund of AIME, Society of Petroleum Engineers, Richardson, TX, USA, 1998.

[79] B. Shibulal, S. N Al-Bahry, Y. M Al-Wahaibi, A. E Elshafie, A. S Al-Bemani, and S. J Joshi, "Microbial enhanced heavy oil recovery by the aid of inhabitant spore-forming bacteria: an insight review," The Scientific World Journal, vol. 2014, Article ID 309159, 12 pages, 2014.

[80] J. D. Desai and I. M. Banat, "Microbial production of surfactants and their commercial potential," Microbiology and Molecular Biology Reviews: Microbiology and Molecular Biology Reviews, vol. 61, no. 1, pp. 47-64, 1997.

[81] P. Singh, Y. Patil, and V. Rale, "Biosurfactant production: emerging trends and promising strategies," Journal of Applied Microbiology, vol. 126, no. 1, pp. 2-13, 2019.

[82] C. Sari, R. Hertadi, M. Gozan, and A. M. Roslan, "Factors affecting the production of biosurfactants and their applications in enhanced oil recovery (EOR). A review," in Proceedings of the IOP Conference Series: Earth and Environmental Science, IOP Publishing, October 2019.

[83] G. Özdemir, S. Peker, and S. Helvaci, "Effect of $\mathrm{pH}$ on the surface and interfacial behavior of rhamnolipids R1 and R2," Colloids and Surfaces A: Physicochemical and Engineering Aspects, vol. 234, no. 1-3, pp. 135-143, 2004.

[84] Y. Al-Wahaibi, S. Joshi, S. Al-Bahry, A. Elshafie, A. AlBemani, and B. Shibulal, "Biosurfactant production by $\mathrm{Ba}$ cillus subtilis B30 and its application in enhancing oil recovery," Colloids and Surfaces B: Biointerfaces, vol. 114, pp. 324-333, 2014.

[85] K. Joshi-Navare, P. Khanvilkar, and A. Prabhune, "Jatropha oil derived sophorolipids: production and characterization as laundry detergent additive," Biochemistry Research International, vol. 2013, Article ID 169797, 11 pages, 2013.

[86] K. V. Sajna, R. K. Sukumaran, H. Jayamurthy et al., "Studies on biosurfactants from Pseudozyma sp. NII 08165 and their potential application as laundry detergent additives," Biochemical Engineering Journal, vol. 78, pp. 85-92, 2013.

[87] N. Kosaric, "Biosurfactants in industry," Pure and Applied Chemistry, vol. 64, no. 11, pp. 1731-1737, 1992.

[88] F. Shahaliyan, A. Safahieh, and H. Abyar, "Evaluation of emulsification index in marine bacteria Pseudomonas sp. and Bacillus sp," Arabian Journal for Science and Engineering, vol. 40, no. 7, pp. 1849-1854, 2015.

[89] B. Lal, "Process for enhanced recovery of crude oil from oil wells using novel microbial consortium," World Intellectual Property Organization, Geneva, Switzerland, Google Patents, 2009.

[90] S. Rassenfoss, "From bacteria to barrels: microbiology having an impact on oil fields," Journal of Petroleum Technology, vol. 63, no. 11, pp. 32-38, 2011.

[91] C. N. Mulligan, "Environmental applications for biosurfactants," Environmental Pollution, vol. 133, no. 2, pp. 183-198, 2005.

[92] D. G. Cooper, C. R. Macdonald, S. J. B. Duff, and N. Kosaric, "Enhanced production of surfactin from Bacillus subtilis by continuous product removal and metal cation additions," Applied and Environmental Microbiology, vol. 42, no. 3, pp. 408-412, 1981.

[93] M. J. McInerney, M. Javaheri, and D. P. Nagle Jr., "Properties of the biosurfactant produced by Bacillus licheniformis strain JF-2," Journal of Industrial Microbiology, vol. 5, no. 2-3, pp. 95-101, 1990. 
[94] D. G. Cooper and B. G. Goldenberg, "Surface-active agents from two Bacillus species," Applied and Environmental Microbiology, vol. 53, no. 2, pp. 224-229, 1987.

[95] G. Jenneman, M. J. McInerney, R. M. Knapp et al., "Halotolerant, biosurfactant-producing Bacillus species potentially useful for enhanced oil recovery," Developments in Industrial Microbiology, vol. 24, 1983.

[96] K. Arima, A. Kakinuma, and G. Tamura, "Surfactin, a crystalline peptide lipid surfactant produced by Bacillus subtilis: isolation, characterization and its inhibition of fibrin clot formation," Biochemical and Biophysical Research Communications, vol. 31, no. 3, pp. 488-494, 1968.

[97] N. S. Shaligram and R. S. Singhal, "Surfactin-a review on biosynthesis, fermentation, purification and applications," Food Technology and Biotechnology, vol. 48, no. 2, pp. 119-134, 2010.

[98] I. M. Banat, A. Franzetti, I. Gandolfi et al., "Microbial biosurfactants production, applications and future potential," Applied Microbiology and Biotechnology, vol. 87, no. 2, pp. 427-444, 2010.

[99] R. S. Bryant, T. E. Burchfield, D. M. Dennis, and D. O. Hitzman, "Microbial-enhanced waterflooding: mink unit project," SPE Reservoir Engineering, vol. 5, no. 1, pp. 9-13, 1990.

[100] R. S. Bryant and J. Douglas, "Evaluation of microbial systems in porous media for EOR," SPE Reservoir Engineering, vol. 3, no. 02, pp. 489-495, 1988.

[101] J. McInerney, T. L. Marsh, X. Zhang et al., Development of More Effective Biosurfactants for Enhanced Oil Recovery, National Petroleum Technology Office, Tulsa, OK, USA, 2003.

[102] C. P. Thomas, M. L. Duvall, E. P. Robertson, K. B. Barrett, and G. A. Bala, "Surfactant-based EOR mediated by naturally occurring microorganisms," SPE Reservoir Engineering, vol. 8, no. 4, pp. 285-291, 1993.

[103] J. Zhang, Q. Xue, H. Gao, H. Lai, and P. Wang, "Production of lipopeptide biosurfactants by Bacillus atrophaeus 5-2a and their potential use in microbial enhanced oil recovery," Microbial Cell Factories, vol. 15, no. 1, pp. 168-11, 2016.

[104] N. J. Hadia, C. Ottenheim, S. Li, N. Q. Hua, L. P. Stubbs, and H. C. Lau, "Experimental investigation of biosurfactant mixtures of surfactin produced by Bacillus subtilis for EOR application," Fuel, vol. 251, pp. 789-799, 2019.

[105] X. Long, N. He, Y. He, J. Jiang, and T. Wu, "Biosurfactant surfactin with $\mathrm{pH}$-regulated emulsification activity for efficient oil separation when used as emulsifier," Bioresource Technology, vol. 241, pp. 200-206, 2017. 